\title{
The effects of licit and illicit recreational drugs on prospective memory: a meta-analytic review
}

\author{
Bradley Platt ${ }^{1}$ - Ciarán O’Driscoll ${ }^{2}$ - Valerie H. Curran ${ }^{1}$ • Peter G. Rendell ${ }^{3} \cdot$ Sunjeev K. Kamboj ${ }^{1}$
}

Received: 9 July 2018 / Accepted: 9 April 2019 / Published online: 16 May 2019

(C) The Author(s) 2019

\begin{abstract}
Rationale There are no recent reports summarising the magnitude of prospective memory (PM) impairments in recreational drug users.

Objective We performed a meta-analysis of studies (with a parallel group design) examining PM performance in users of common recreational drugs (including alcohol and tobacco) who were not intoxicated during testing. Studies were also evaluated for the presence of methodological bias.

Methods Twenty-seven studies were included in the meta-analysis following literature searches of MEDLINE, EMBASE and PsycINFO. Effect sizes (standardised mean difference; SMD) were calculated separately for the effects of alcohol, cannabis, ecstasy, methamphetamine and tobacco use. The influences of drug use and study characteristics on effect sizes were explored using meta-regressions. Sources of study bias were also assessed.

Results Heavy drinkers and regular drug users tended to perform worse than controls on event and time-based PM tasks. Effect sizes (standardised mean differences; SMDs) for event-based PM impairment across the different drug-using groups/heavy drinkers ranged between -1.10 and -0.49 , with no 95\% CI crossing 0.00. SMDs for time-based PM ranged between -0.98 and -0.70 . Except for the CIs associated with the ES for smokers' time-based PM performance, no CIs crossed 0.00.

Conclusions Although all drug-using groups showed moderate-large impairments in event and time-based PM, effect sizes had low precision and moderate-high levels of heterogeneity. In addition, several methodological and reporting issues were identified in the majority of studies. As such, considerable uncertainty remains regarding the role of confounds and the magnitude of PM impairments in non-intoxicated recreational drug users.
\end{abstract}

Keywords Prospective memory $\cdot$ Alcohol $\cdot$ Cannabis $\cdot$ Ecstasy $\cdot$ Methadone $\cdot$ Tobacco $\cdot$ Opiate $\cdot$ Methamphetamine

Electronic supplementary material The online version of this article (https://doi.org/10.1007/s00213-019-05245-9) contains supplementary material, which is available to authorized users.

Bradley Platt

bradley.platt@me.com

1 Clinical Psychopharmacology Unit, University College London, London, UK

2 Institute of Cognitive Neuroscience, University College London, London, UK

3 Cognition and Emotion Research Centre, Australian Catholic University, Melbourne, Australia

\section{Introduction}

The maladaptive use of recreational substances is a major international public health concern. Regular and/or excessive substance use including heavy drinking and smoking is associated with significant levels of mortality, morbidity and social problems, with tobacco and alcohol use being two of the leading risk factors for disability and mortality (World Health Organization 2009). Most psychoactive compounds are neurotoxic, especially after large or repeated doses, and in the case of illicit drugs, often contain adulterants with unknown associated toxicity. As such, impairments in cognitive functioning following acute or chronic drug use (Fernández-Serrano et al. 2011) and consequent interference with daily activities (Grafman and Litvan 1999) is perhaps unsurprising. One domain of special relevance to everyday functioning, for which 
there is mounting experimental evidence of drug-induced impairments, is prospective memory (PM).

PM refers to the ability to remember to carry out intended actions in the future (Brandimonte et al. 1996). According to McDaniel and Einstein's (2000) multi-process model, PM relies on either spontaneous retrieval (in which the occurrence of a triggering event promotes retrieval of the intended action from long-term memory) or strategic monitoring (in which the participant actively monitors the environment for triggering cues). When cognitive processes involved in on-going behaviour support the processes involved in PM, the tasks are defined as 'focalcue' tasks and are thought to rely on spontaneous retrieval. Alternatively, when these do not support the processes involved in PM, the relevant tasks are defined as 'non-focal' and depend upon strategic monitoring. In addition, a distinction is made between event- and time-based PM tasks with the former relying more on spontaneous, cue-driven retrieval and the latter on strategic monitoring (Einstein et al. 1995). Whilst event-based tasks require participants to perform an intention in response to an external cue (e.g. "buy a birthday present at the shopping centre"), time-based tasks require participants to perform an intention at a specific time or after a delay (e.g. call the plumber at $2 \mathrm{pm})$.

Severe impairments in PM likely have commensurately severe consequences for daily functioning through a failure to enact intended (adaptive) actions. In those individuals who are attempting to refrain from drug use, PM impairments may also interfere with the ability to apply planned relapse prevention strategies. However, while the negative consequences of psychoactive drug use on PM are commonly reported, methodological limitations in a significant amount of existing research mean that the nature and severity of PM problems that are attributable to specific drugs remains unclear.

Subjective measures of meta-cognition suggest impairments in PM amongst heavy drinkers (Heffernan et al. 2002; Ling et al. 2003, 2010), cannabis users (Montgomery and Fisk 2007; Fisk and Montgomery 2008) and ecstasy users (Heffernan et al. 2001a, b; Rodgers et al. 2001, 2003; Hadjiefthyvoulou et al. 2010). However, the self-report measures used to investigate these metacognitive effects may be susceptible to biases related to lifestyle (Uttl and Kibreab 2011), anxiety (Bedi and Redman 2008a), retrospective memory (Brown and Craik 2000) and social acquiescence (Ling et al. 2010). Furthermore, self-reported complaints about PM have limited predictive validity and are, at best, only weakly correlated with performance on everyday PM-dependent tasks (Hertzog et al. 2000).

In light of these measurement issues, some studies have investigated drug effects on PM with behavioural rather than self-report measures. Similar to the above findings, these studies have shown, for example, that acute intoxication from alcohol (Leitz et al. 2009; Montgomery et al. 2011; Paraskevaides et al. 2010) and ecstasy (Kuypers et al. 2013;
Ramaekers et al. 2009; van Wel et al. 2011) adversely affects PM abilities. However, there are likely substantial differences between the pharmacological effects and pharmacokinetic profiles of single doses of pharmaceutical-grade compounds administered in laboratory settings and those used recreationally in naturalistic contexts. Thus, while lab-based acute drug studies enable tight experimental control, they provide little insight into whether PM deficits extend beyond the acutely or sub-acutely intoxicated state.

In this study, we therefore use a meta-analytic approach to review the chronic effects of psychoactive drugs on PM in non-intoxicated users. In addition to determining effect sizes of PM impairment, reviewed studies were also assessed for susceptibility to bias and effects of important confounds such as premorbid intelligence and age (Cherry and LeCompte 1999). We focus on the effects of licit and illicit drugs on event and time-based PM performance.

\section{Method}

\section{Search methods}

Articles were identified through a literature search of MEDLINE (1946 to March 2017), EMBASE (1980 to March 2017) and PsycINFO (1806 to March 2017), using keywords and synonyms of the following common categories of licit and illicit recreational drugs: 'alcohol' OR 'cannabis' OR 'tobacco' OR 'amphetamine' OR 'cocaine' OR 'opioid.' The 'AND' operator was used for the keyword: 'prospective memory' (see supplementary material for search strategy: S1). 'Binge drink?' was included as an additional alcohol-specific search term. Electronic searches were supplemented by hand searches of reference lists, although this yielded no additional studies.

Studies were included if they were full-text journal articles and met the following criteria: (1) were published in an English language peer-reviewed journal, (2) the primary aim was to examine the effects of psychoactive drug-use on PM performance, (3) used a parallel group design with a control condition (consisting of non-using or light and/or infrequent users) and experimental condition (participants who frequently and/or excessively used the primary drug), (4) evaluated PM using a behavioural rather than self-report measure and (5) used a behavioural task that tapped the full complement of cognitive activities required for PM (see below). The process of study selection and exclusion followed PRISMA guidelines (Fig. 1).

\section{Inclusion criteria for prospective memory tasks}

According to influential conceptual models of the cognitive processes involved in successful PM performance, there are 
Fig. 1 Primsa flowchart
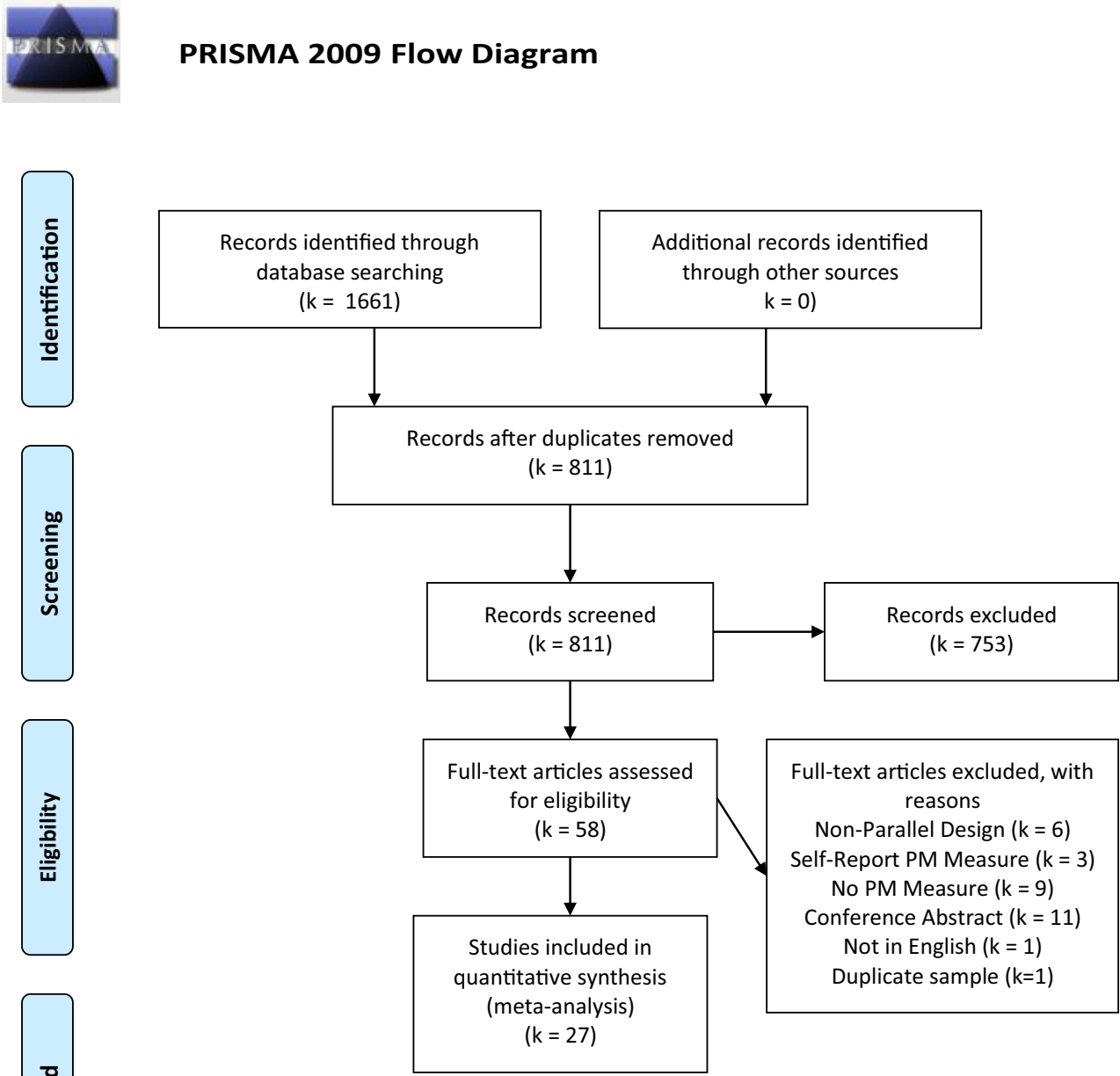

four sequential stages in the execution of an intended future action (e.g. Knight 1998). The initial stage involves the formation and encoding of an intention and action plan as well as an evaluation of potential factors that could optimise or impede performance. Secondly, there is a retention interval where other cognitive activities can potentially interfere with the rehearsal of the encoded intention. The third stage involves self-initiated retrieval of the intention, where a target cue triggers the effortful and controlled search for the intention in memory. Finally, actual retrieval and execution of the intention occurs. These features of PM require that valid objective measures of PM incorporate the constituent cognitive processes or activities of these four stages. In particular, PM tasks should incorporate a delay between the encoding and execution of the intention with the delay filled with a secondary ongoing task. Furthermore the task must incorporate cues or prompts to initiate intention retrieval without external reminders. For the current review, tasks that did not incorporate all of these features were not considered to be construct-valid assessments of the full range of PM competencies, and studies using such tasks were therefore not included.

\section{Data extraction}

Quantitative data (mean, standard deviation and sample size) on PM task performance were extracted and coded by PM type (event vs. time) by the first and second authors.

Table 1 outlines salient participants and study characteristics extracted from included studies. We also determined whether reliability and validity of PM tasks had been formally established and rated the tasks accordingly (see below). These ratings were used in a moderator analysis. Fifteen distinct tasks were used to assess prospective memory across the included studies (Table 1). These were the Cambridge Prospective Memory Test (CAMPROMPT; Wilson et al. 2005), Video-Based Prospective Memory Task (V-B PMT; Titov and Knight 2001), Memory for Intentions Screening Test (MIST; Raskin et al. 2010), belonging subtest of the Rivermead Behavioural Memory Test (RBMT; 
Table 1 Demographic and study details by drug group

\begin{tabular}{|c|c|c|c|c|c|c|c|c|c|}
\hline \multirow[b]{2}{*}{ Study } & \multicolumn{3}{|l|}{ Experimental } & \multicolumn{2}{|l|}{ Control } & \multicolumn{2}{|c|}{ Prospective memory measure } & \multirow[b]{2}{*}{$\begin{array}{l}\text { Measure } \\
\text { quality }\end{array}$} & \multirow{2}{*}{$\begin{array}{l}\text { Drug use } \\
\text { Lifetime } \\
\text { dosage }\end{array}$} \\
\hline & Subgroups & Male:Female & $\begin{array}{l}\text { Age } \\
\text { mean(SD) }\end{array}$ & Male:Female & $\begin{array}{l}\text { Age } \\
\text { mean }(\mathrm{SD})\end{array}$ & Name & $\begin{array}{l}\text { Event or } \\
\text { time }\end{array}$ & & \\
\hline \multicolumn{10}{|l|}{ Alcohol } \\
\hline Griffiths et al. (2012) & None & $16 / 8$ & $\begin{array}{l}42.00 \\
\quad(8.74)\end{array}$ & $16 / 8$ & $41.90(8.63)$ & VW & $\begin{array}{l}\text { Event and } \\
\text { time }\end{array}$ & 1 & 3 \\
\hline $\begin{array}{l}\text { Heffernan et al. } \\
\text { (2010a) }\end{array}$ & None & $7 / 14$ & $\begin{array}{l}18.70 \\
(0.46)\end{array}$ & $5 / 24$ & $18.60(0.48)$ & PRVP & Event & 2 & 2 \\
\hline $\begin{array}{l}\text { Heffernan and } \\
\text { O'Neill (2012) }\end{array}$ & None & $14 / 14$ & $\begin{array}{l}24.10 \\
\quad(5.30)\end{array}$ & $12 / 16$ & $24.30(5.45)$ & CAMPROMPT & $\begin{array}{l}\text { Event and } \\
\text { time }\end{array}$ & 2 & 2 \\
\hline Marshall et al. (2016) & None & $15 / 25$ & $\begin{array}{l}22.30 \\
(4.10)\end{array}$ & $6 / 19$ & $22.55(4.16)$ & CAMPROMPT & $\begin{array}{l}\text { Event and } \\
\text { time }\end{array}$ & 2 & 2 \\
\hline $\begin{array}{l}\text { Laloyaux et al. } \\
\text { (2012) }\end{array}$ & None & $17 / 3$ & $\begin{array}{l}46.0 \\
\quad(10.72)\end{array}$ & $17 / 3$ & $45.8(10.63)$ & CST & Event & 3 & 3 \\
\hline Platt et al. (2016) & None & $11 / 8$ & $\begin{array}{l}25.55 \\
\quad(2.36)\end{array}$ & $13 / 5$ & $27.60(1.59)$ & VW & $\begin{array}{l}\text { Event and } \\
\text { time }\end{array}$ & 1 & 2 \\
\hline $\begin{array}{l}\text { Weinborn et al. } \\
\text { (2011) }\end{array}$ & None & $9 / 12$ & $\begin{array}{l}19.50 \\
(2.10)\end{array}$ & $11 / 20$ & $19.70(1.6)$ & MIST & $\begin{array}{l}\text { Event and } \\
\text { time }\end{array}$ & 1 & 1 \\
\hline \multicolumn{10}{|l|}{ Cannabis } \\
\hline $\begin{array}{l}\text { Bartholomew et al. } \\
\text { (2010) }\end{array}$ & None & $20 / 25$ & $\begin{array}{l}\text { Not } \\
\text { report- } \\
\text { ed }\end{array}$ & $17 / 28$ & Not reported & V-B PMT & Event & 2 & 2 \\
\hline $\begin{array}{l}\text { Bedi and Redman } \\
\text { (2008b) }\end{array}$ & None & $26 / 22$ & $\begin{array}{l}21.70 \\
\quad(3.50)\end{array}$ & $21 / 19$ & $23.10(3.70)$ & $\mathrm{DC}$ & Event & 3 & 2 \\
\hline \multirow[t]{2}{*}{ Cuttler et al. (2012) } & Experimental/ & $19 / 29$ & $\begin{array}{l}20.75 \\
\quad(2.78)\end{array}$ & $10 / 38$ & $19.71(2.59)$ & FT & Event & 2 & 1 \\
\hline & Chronic users & $25 / 23$ & $\begin{array}{l}20.42 \\
\quad(2.52)\end{array}$ & & & & & & \\
\hline $\begin{array}{l}\text { Gallagher et al. } \\
\text { (2014) }\end{array}$ & None & $17 / 21$ & $\begin{array}{l}21.47 \\
\quad(3.00)\end{array}$ & $17 / 48$ & $20.64(2.23)$ & $\begin{array}{l}\text { PRPMT and } \\
\text { FTBPT }\end{array}$ & $\begin{array}{l}\text { Event and } \\
\text { time }\end{array}$ & 3 & 2 \\
\hline $\begin{array}{l}\text { Hadjiefthyvoulou } \\
\text { et al. (2011b) }\end{array}$ & None & $5 / 7$ & $\begin{array}{l}21.92 \\
\quad(1.56)\end{array}$ & $2 / 16$ & $20.44(2.28)$ & CAMPROMPT & $\begin{array}{l}\text { Event and } \\
\text { time }\end{array}$ & 2 & 2 \\
\hline $\begin{array}{l}\text { McHale and Hunt } \\
\text { (2008) }\end{array}$ & None & $10 / 8$ & $\begin{array}{l}21.60 \\
(1.10)\end{array}$ & $10 / 10$ & $21.40(1.60)$ & $\begin{array}{l}\text { SIPMT and long } \\
\text { interval }\end{array}$ & $\begin{array}{l}\text { Event and } \\
\text { time }\end{array}$ & 3 & $?$ \\
\hline $\begin{array}{l}\text { Montgomery et al. } \\
\text { (2012) }\end{array}$ & None & $13 / 7$ & $\begin{array}{l}21.05 \\
\quad(1.79)\end{array}$ & $7 / 13$ & $20.30(4.65)$ & JAAMT & $\begin{array}{l}\text { Event and } \\
\text { time }\end{array}$ & 3 & 3 \\
\hline \multicolumn{10}{|l|}{ Ecstasy/MDMA } \\
\hline $\begin{array}{l}\text { Bedi and Redman } \\
(2008 \mathrm{a}, \mathrm{b})\end{array}$ & None & $24 / 21$ & $\begin{array}{l}22.80 \\
(3.0)\end{array}$ & $21 / 19$ & $23.10(3.70)$ & DC & Event & 3 & 2 \\
\hline $\begin{array}{l}\text { Gallagher et al. } \\
\text { (2014) }\end{array}$ & None & $51 / 51$ & $\begin{array}{l}21.85 \\
\quad(2.98)\end{array}$ & $17 / 48$ & $20.64(2.23)$ & $\begin{array}{l}\text { PRPMT and } \\
\text { FTBPT }\end{array}$ & $\begin{array}{l}\text { Event and } \\
\text { time }\end{array}$ & 3 & 2 \\
\hline $\begin{array}{l}\text { Hadjiefthyvoulou } \\
\text { et al. (2011a) }\end{array}$ & None & $14 / 28$ & $\begin{array}{l}21.67 \\
(3.61)\end{array}$ & $5 / 26$ & $21.03(3.25)$ & $\begin{array}{l}\text { Belonging test } \\
\text { of RBMT }\end{array}$ & Event & 1 & 3 \\
\hline $\begin{array}{l}\text { Hadjiefthyvoulou } \\
\text { et al. (2011b) }\end{array}$ & None & $17 / 12$ & $\begin{array}{l}21.17 \\
\quad(1.79)\end{array}$ & $2 / 16$ & $20.44(2.28)$ & CAMPROMPT & $\begin{array}{l}\text { Event and } \\
\text { time }\end{array}$ & 2 & 3 \\
\hline $\begin{array}{l}\text { Montgomery } \\
\text { et al. (2010) }\end{array}$ & None & $13 / 10$ & $\begin{array}{l}23.22 \\
(4.56)\end{array}$ & $9 / 17$ & $21.92(2.27)$ & JAAMT & $\begin{array}{l}\text { Event and } \\
\text { time }\end{array}$ & 3 & 2 \\
\hline Rendell et al. (2007) & None & $14 / 13$ & $\begin{array}{l}21.30 \\
(1.96)\end{array}$ & $15 / 19$ & $20.60(1.40)$ & VW & $\begin{array}{l}\text { Event and } \\
\text { time }\end{array}$ & 1 & $?$ \\
\hline $\begin{array}{l}\text { Weinborn et al. } \\
\text { (2011) }\end{array}$ & None & $12 / 19$ & $\begin{array}{l}21.40 \\
(3.30)\end{array}$ & $11 / 20$ & $19.70(1.60)$ & MIST & $\begin{array}{l}\text { Event and } \\
\text { time }\end{array}$ & 1 & 1 \\
\hline Zakzanis et al. (2003) & None & $12 / 3$ & $\begin{array}{l}24.10 \\
\quad(5.60)\end{array}$ & $14 / 3$ & $23.40(2.00)$ & $\begin{array}{l}\text { Belonging test } \\
\text { of RBMT }\end{array}$ & Event & 1 & 2 \\
\hline \multicolumn{10}{|l|}{ Methamphetamine } \\
\hline Iudicello et al. (2011) & None & $36 / 3$ & $\begin{array}{l}41.60 \\
\quad(8.80)\end{array}$ & $11 / 15$ & $40.60(13.80)$ & MIST & $\begin{array}{l}\text { Event and } \\
\text { time }\end{array}$ & 1 & 2 \\
\hline Rendell et al. (2009) & None & $12 / 8$ & $\begin{array}{l}27.50 \\
(5.21)\end{array}$ & $12 / 8$ & $28.20(5.00)$ & VW & $\begin{array}{l}\text { Event and } \\
\text { time }\end{array}$ & 1 & 2 \\
\hline
\end{tabular}

Tobacco 
Table 1 (continued)

\begin{tabular}{|c|c|c|c|c|c|c|c|c|c|}
\hline \multirow[b]{2}{*}{ Study } & \multicolumn{3}{|l|}{ Experimental } & \multicolumn{2}{|l|}{ Control } & \multicolumn{2}{|c|}{ Prospective memory measure } & \multirow[b]{2}{*}{$\begin{array}{l}\text { Measure } \\
\text { quality }\end{array}$} & \multirow{2}{*}{$\begin{array}{l}\text { Drug use } \\
\text { Lifetime } \\
\text { dosage }\end{array}$} \\
\hline & Subgroups & Male:Female & $\begin{array}{l}\text { Age } \\
\text { mean(SD) }\end{array}$ & Male:Female & $\begin{array}{l}\text { Age } \\
\text { mean(SD) }\end{array}$ & Name & $\begin{array}{l}\text { Event or } \\
\text { time }\end{array}$ & & \\
\hline Behrendt et al. (2015) & None & $14 / 9$ & $\begin{array}{l}25.30 \\
\quad(4.26)\end{array}$ & $8 / 12$ & $21.80(2.63)$ & SET & Event & 3 & 2 \\
\hline $\begin{array}{l}\text { Heffernan et al. } \\
\text { (2010b) }\end{array}$ & None & $5 / 13$ & $\begin{array}{l}25.20 \\
(5.28)\end{array}$ & $3 / 19$ & $22.50(4.21)$ & CAMPROMPT & $\begin{array}{l}\text { Event and } \\
\text { time }\end{array}$ & 2 & 2 \\
\hline \multirow[t]{2}{*}{$\begin{array}{l}\text { Heffernan et al. } \\
\text { (2012) }\end{array}$} & Smoker & $11 / 16$ & $\begin{array}{l}22.40 \\
(5.13)\end{array}$ & $3 / 21$ & $19.00(2.22)$ & RWPMT & Event & & \\
\hline & $\begin{array}{l}\text { Previous } \\
\quad \text { Smoker }\end{array}$ & $3 / 15$ & $\begin{array}{l}23.70 \\
(5.99)\end{array}$ & & & & & 3 & 2 \\
\hline \multirow[t]{2}{*}{$\begin{array}{l}\text { Heffernan et al. } \\
\text { (2013) }\end{array}$} & Second-Hand & $13 / 14$ & $\begin{array}{l}22.00 \\
(1.46)\end{array}$ & $10 / 18$ & $22.80(6.03)$ & CAMPROMPT & $\begin{array}{l}\text { Event and } \\
\text { time }\end{array}$ & & \\
\hline & $\begin{array}{l}\text { Current } \\
\text { Smoker }\end{array}$ & $12 / 12$ & $\begin{array}{l}24.4 \\
\quad(4.79)\end{array}$ & & & & & & \\
\hline $\begin{array}{l}\text { Heffernan et al. } \\
\text { (2013) }\end{array}$ & None & $14 / 25$ & $\begin{array}{l}21.10 \\
\quad(2.63)\end{array}$ & $18 / 21$ & $20.60(2.10)$ & V-B PMT & Event & 2 & 2 \\
\hline $\begin{array}{l}\text { Heffernan et al. } \\
\text { (2014a) }\end{array}$ & None & $18 / 6$ & $\begin{array}{l}21.20 \\
(2.04)\end{array}$ & $14 / 10$ & $20.50(0.97)$ & CAMPROMPT & $\begin{array}{l}\text { Event and } \\
\text { time }\end{array}$ & 2 & 2 \\
\hline Jansari et al. 2013 & None & $15 / 21$ & $\begin{array}{l}27.73 \\
\quad(8.27)\end{array}$ & $18 / 18$ & $\begin{array}{l}28.94 \\
\quad(11.50)\end{array}$ & JAAMT & Event & 3 & 2 \\
\hline $\begin{array}{l}\text { McHale and Hunt } \\
\text { (2008) }\end{array}$ & None & $10 / 10$ & $\begin{array}{l}21.20 \\
\quad(1.28)\end{array}$ & $10 / 10$ & $21.40(1.60)$ & SIPMT & Event & 3 & $?$ \\
\hline Marshall et al. (2016) & None & $6 / 14$ & $\begin{array}{l}27.15 \\
(6.80)\end{array}$ & $6 / 19$ & No report & CAMPROMPT & $\begin{array}{l}\text { Event and } \\
\text { time }\end{array}$ & 2 & 2 \\
\hline \multicolumn{10}{|l|}{ Opiates } \\
\hline Terrett et al. (2014) & & $18 / 8$ & $\begin{array}{l}38.31 \\
\quad(7.46)\end{array}$ & $16 / 14$ & 39.47 (7.94) & VW & $\begin{array}{l}\text { Event and } \\
\text { time }\end{array}$ & 1 & 1 \\
\hline
\end{tabular}

Notes: Cambridge Prospective Memory Test (CAMPROMPT; Wilson et al. 2005), Video-Based Prospective Memory Task (V-B PMT; Titov and Knight 2001), Memory for Intentions Screening Test (MIST; Raskin et al. 2010), belonging subtest of the Rivermead Behavioural Memory Test (RBMT; Wilson et al. 1985), Six Elements Test (SET; Kliegel et al. 2007), Designated Crosses Test (DC; Bedi and Redman 2008b), Virtual Week (VW; Rendell and Craik 2000), Fruit Test (FT; Cuttler et al. 2012), Pattern Test (Hadjiefthyvoulou et al. 2010), Pattern Recognition Prospective Memory Task (PRPMT; Gallagher et al. 2014), Fatigue Time-Based Prospective Memory Test (FTBPT; Gallagher et al. 2014), Computerised Shopping Task (CDT; Laloyaux et al. 2012), Short-Interval Prospective Memory Task (SIPMT; McHale and Hunt 2008), Jansari-Agnew-Akesson-Murphy Task (JAAMT; Jansari et al. 2004), and Prospective Remembering Video Procedure (PRVP; Seed et al. 2005)

Wilson et al. 1985), Six Elements Test (SET; Kliegel et al. 2007), Designated Crosses Test (DC; Bedi and Redman 2008b), Virtual Week (VW; Rendell and Craik 2000), Fruit Test (FT; Cuttler et al. 2012), Pattern Test (Hadjiefthyvoulou et al. 2010), Pattern Recognition Prospective Memory Task (PRPMT; Gallagher et al. 2014), Fatigue Time-Based Prospective Memory Test (FTBPT; Gallagher et al. 2014), Computerised Shopping Task (CDT; Laloyaux et al. 2012), Short-Interval Prospective Memory Task (SIPMT; McHale and Hunt 2008), Jansari-AgnewAkesson-Murphy Task (JAAMT; Jansari et al. 2014) and Prospective Remembering Video Procedure (PRVP; Seed et al. 2005). Ratings of 'established psychometric properties' were based on previously reported psychometric properties of the tasks (see S4) using a 1-3 scale (1 = measures with acceptable testretest reliability and concurrent validity; $2=$ concurrent validity (objective measures) and questionable or no evidence of testretest reliability or split-half reliability, and $3=$ no evidence of reliability and where concurrent validity was based on selfreport measures). In four studies, the Virtual Week was used to assess prospective memory which makes a distinction between 'regular' and 'irregular' PM tasks (Griffiths et al. 2012; Platt et al. 2016; Rendell et al. 2007, 2009). Here, we only extracted participants' 'irregular' PM performance as the task demands are comparable with other measures of PM.

In addition, estimated lifetime drug/alcohol dose was determined from available information in each study. Within subgroup, $z$-scores were calculated. Participant samples were then rated as $1=$ low $(<-1 \mathrm{SD}), 2=$ moderate $(-1$ to $1 \mathrm{SD})$, and $3=$ high (>1 SD) lifetime exposure to a specific drug. There was no relevant data to estimate lifetime dose in two studies (McHale and Hunt 2008; Rendell et al. 2007).

\section{Study quality rating}

We also rated studies on robustness of design and susceptibility to bias (rating was conducted independently by the first two authors; disagreements in ratings were resolved through discussion). Bias in participant selection, case definition (i.e. allocation 
to groups based on objective/standardised measures of drug-use) and blinding of participants and investigators was assessed (Downs and Black 1998; Sanderson et al. 2007; Wells et al. 2011). Additional items on methodological quality on domains considered by the authors to be especially relevant for drug studies of PM were also included in the quality rating scheme (matching of groups on age, intelligence, drug-use and verification of non-intoxication). All domains of bias were assigned a high, low or unclear risk of bias. If information was not available in the publication, quality items were coded as 'not available.' Details on criteria for quality ratings and a summary of the authors' judgements about each risk of bias item for each included study are included in the supplementary section (S2 and S3).

\section{Analyses}

Effect sizes based on the standardised mean difference (SMD) between control and drug-using groups were calculated using random effects models. Larger negative effect sizes indicated that the mean performance of the substance-using group was lower than the control group. Effect sizes in the range $0.20-0.49$ were defined as small, $0.50-0.79$ as moderate and $\geq 0.80$ as large (Cohen 1988).

Analyses were conducted using the Cochrane Collaboration's Review Manager software (RevMan version 5.3), and in $R$ using the metafor package (Viechtbauer 2010). Random effects models (maximum likelihood estimator) were used, with the assumption that studies had different true effect sizes, as such the combined effect size represents a distribution of effect sizes (Higgins and Green 2011). Heterogeneity was assessed using a point estimate of the amongst-study variance of true effects $\left(\tau^{2}\right)$ and the approximate proportion of total variability $\left(I^{2}\right)$, where an $I^{2}$ of $25 \%, 50 \%$ and $75 \%$ is considered small, moderate and large, respectively (Higgins 2008). When moderate or high heterogeneity was observed, interpretation emphasised the range of likely combined effect sizes (confidence intervals) rather than a single-summary effect size. Sensitivity analysis involved stepwise removal of studies to assess the impact of their removal on high levels of heterogeneity.

Random effects meta-regressions (maximum likelihood estimator) were conducted to relate the effect sizes to characteristics of the studies (lifetime dosage and measures used). This form of analysis can help to explain the heterogeneity between studies providing estimates of the difference in effect between studies rated on the three levels of each categorical moderator variable. Due to the number of studies, it was not possible to conduct analyses on specific drug groups.

\section{Results}

Twenty-seven studies fulfilled inclusion criteria and provided data for meta-analyses. Figure 2 summarises risk of bias ratings for all included studies. Certain methodological features were consistently rated as having a high risk of bias (e.g. population sourcing; case definition). For other features (e.g. blinding of experimenters and participants), reporting was poor (unclear bias). Alternatively, a number of study features were less commonly associated with bias across the studies as a whole (comparability of control and drug-using groups in terms of participant age, intelligence and alcohol use).

Forest plots for event and time-based PM comparisons are displayed in Figs. 3 and 4. Means, standard deviations and
Fig. 2 Risk of bias summary: Prevalence of bias for each domain presented as percentage of studies with high, low or unclear risk of bias

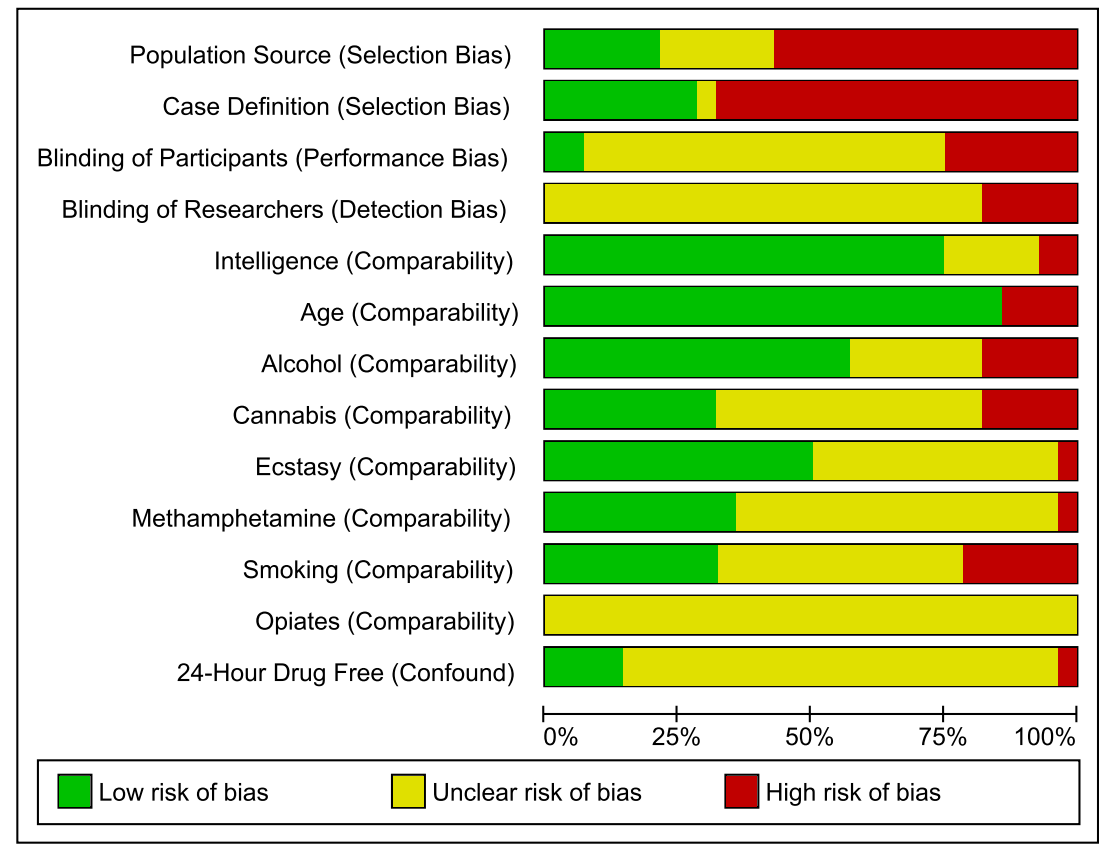




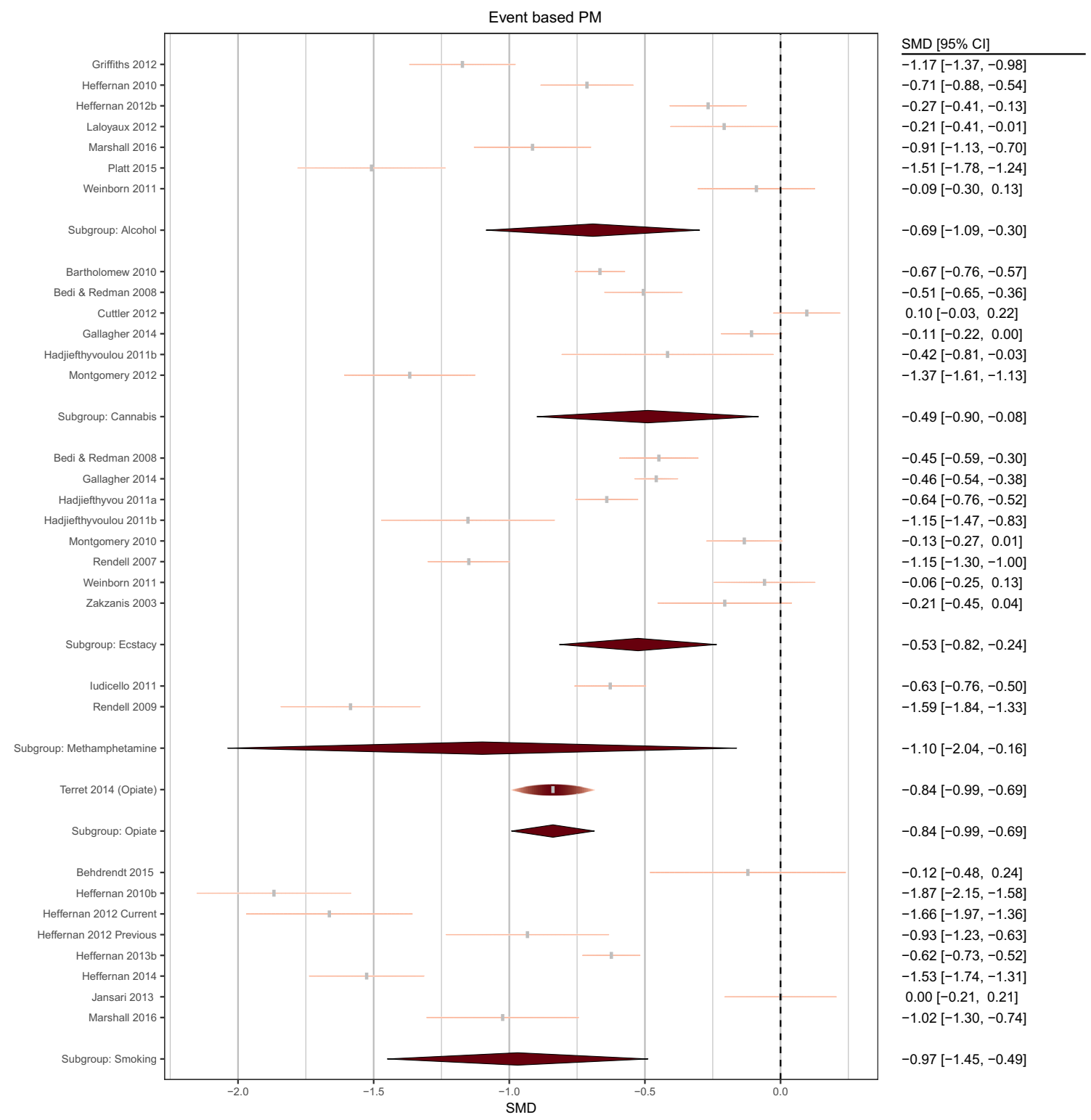

Fig. 3 Forest plot of comparisons for event-based PM tasks across drug conditions. The width of each node is identical to the width of the confidence interval. The height of each raindrop is scaled with respect to its relative meta-analytic weight considering all studies within the subgroup

sample sizes used in effect size calculations are included in the supplementary material (S5 and S6).

\section{Alcohol}

Seven studies compared heavy drinkers (total $n=172$ ), with an estimated total lifetime use ranging between 800 and 20,000 units, with control groups (total $n=148$ ) on eventbased PM performance. As indicated in Fig. 3, alcohol groups performed worse than control groups and the true effect size lays in the small to large range. There was a moderate degree of heterogeneity $\left(\tau^{2}=0.164, I^{2}=62 \%\right)$ although no individual study's removal appreciably reduced heterogeneity.

Of the seven alcohol studies, five also compared heavy drinkers (total $n=131$ ) with control groups (total $n=99$ ) on time-based PM (Fig. 4). Again, alcohol groups performed worse than controls, with the true effect ranging from approximately zero to large. There was a high level of heterogeneity $\left(\tau^{2}=0.7\right.$, $I^{2}=87 \%$ ). However, a single study (Platt et al. 2016) appeared to disproportionately contribute to heterogeneity. Its removal not only eliminated heterogeneity $\left(\tau^{2}=0, I^{2}=0 \%\right)$, but also reduced the overall effect size from SMD $=-0.84(95 \% \mathrm{CI} ;-1.70$ to 0.02 ) to -0.43 (95\% CI; -0.72 to -0.13$)$.

\section{Cannabis}

Six studies compared cannabis users (total $n=205$ ) with an estimated total lifetime use ranging between 312 and 10,699 joints, with healthy controls (total $n=151$ ), on event-based PM tasks, with cannabis groups performing worse, and the likely true effect 


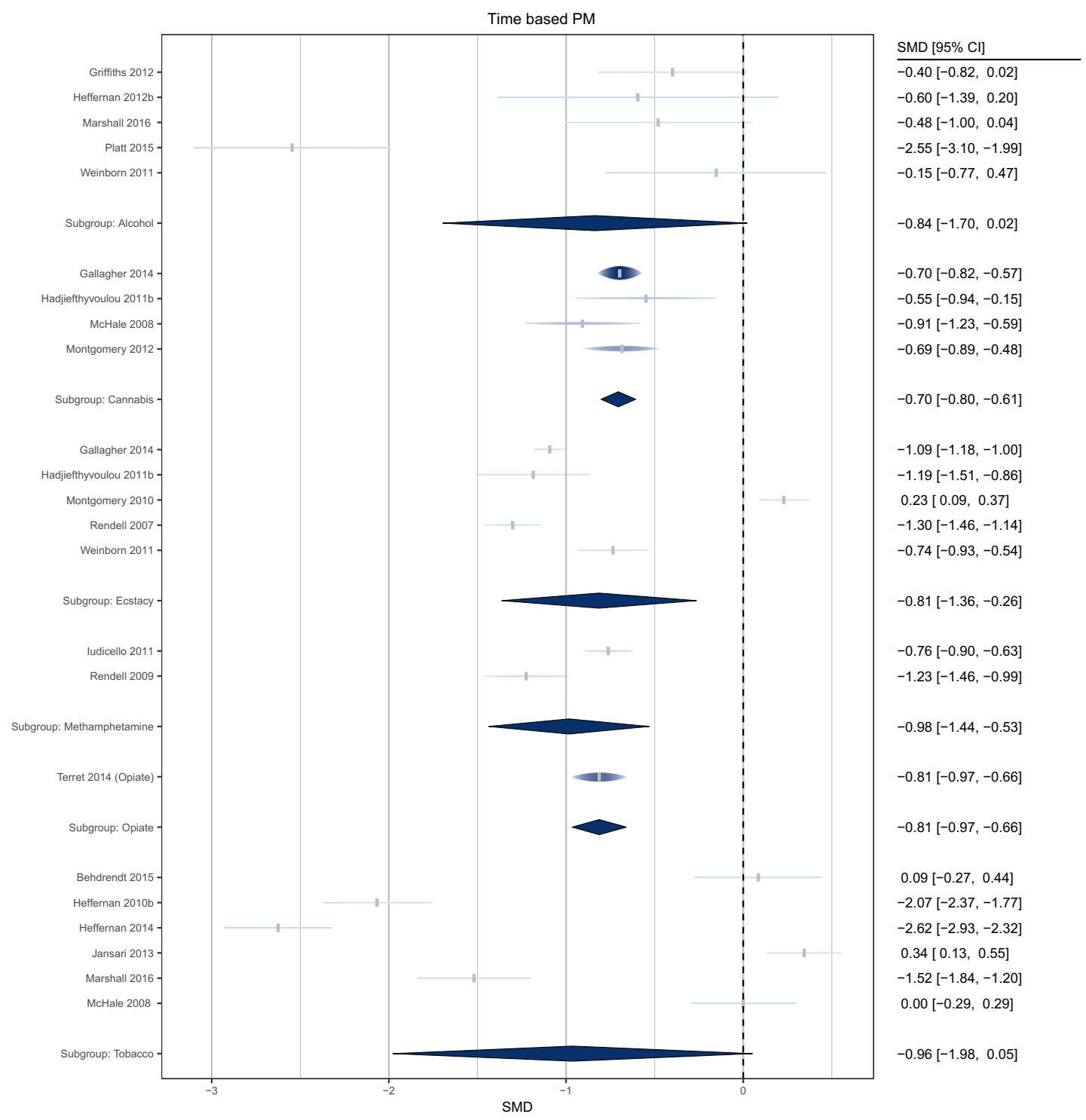

Fig. 4 Forest plot of comparisons for time-based PM tasks across drug conditions. The width of each node is identical to the width of the confidence interval. The height of each raindrop is scaled with respect to its relative meta-analytic weight considering all studies within the subgroup

size between negligible and large. Accordingly, there was high heterogeneity $\left(\tau^{2}=0.159, I^{2}=68 \%\right)$. Excluding Montgomery et al. (2012) not only reduced heterogeneity $\left(\tau^{2}=0.053, I^{2}=\right.$ $43 \%)$ but also reduced the effect size from $\mathrm{SMD}=-0.49(95 \%$ $\mathrm{CI} ;-0.90$ to -0.08$)$ to $\mathrm{SMD}=-0.31(95 \% \mathrm{CI} ;-0.63$ to 0.004).

Four studies compared a cannabis-using group (total $n=$ 88 ) with healthy controls (total $n=71$ ), on a time-based PM task. There was a moderate combined effect size, with the cannabis groups performing worse, and no heterogeneity $\left(\tau^{2}=0, I^{2}=0 \%\right)$.

\section{Ecstasy}

Eight studies compared an ecstasy group $(n=272)$ with varying histories of quantities of ecstasy consumed (estimated total lifetime use ranging between 30 and 668 tablets) with healthy controls $(n=196)$, on an event-based PM task, with ecstasy groups performing worse, displaying a small to large effect. There was moderate heterogeneity $\left(\tau^{2}=0.065, I^{2}=45 \%\right)$.

Five studies compared an ecstasy group (total $n=213$ ) with healthy controls (total $n=127$ ), on a time-based PM task, with ecstasy groups performing worse, which also indicated a small 
to large effect. There was high heterogeneity $\left(\tau^{2}=0.32, I^{2}=\right.$ $80 \%$ ). Excluding Montgomery et al. (2010) explained the heterogeneity $\left(\tau^{2}=0, I^{2}=0 \%\right)$ and increased the effect size from $\mathrm{SMD}=-0.81(95 \% \mathrm{CI} ;-1.36$ to -0.26$)$ to $\mathrm{SMD}=-1.08$ $(95 \% \mathrm{CI} ;-1.36$ to -0.809$)$.

\section{Methamphetamine}

Two studies compared a methamphetamine group with an estimated total lifetime use ranging between 720 and $1058 \mathrm{~g}$, (total $n=59$ ) with healthy controls (total $n=46$ ), on an eventbased PM task, with methamphetamine groups performing worse, indicating a small to large effect. There was high heterogeneity $\left(\tau^{2}=0.359, I^{2}=78 \%\right)$.

The same two studies compared groups on a time-based PM task, with methamphetamine groups performing worse, indicating a moderate to large effect size with low heterogeneity $\left(\tau^{2}=0.013, I^{2}=12 \%\right)$.

\section{Opiates}

One study compared an opiate group (long-term heroin users enrolled in opioid replacement treatment estimated lifetime use of $4272 \mathrm{~g} ; n=26)$ with controls $(n=30)$ on an eventand time-based task, both indicating a moderate to large effect, with the opiate group performing worse than healthy controls.

\section{Smoked tobacco/nicotine}

Seven studies (eight group comparisons) compared a tobaccosmoking group (total $n=175$ ), with an estimated total lifetime ranging between 10,610 and 117,511 cigarettes, with healthy controls (total $n=153$ ), on an event-based PM task. These indicated that tobacco groups tended to perform worse than controls, with a moderate to large combined effect and moderate heterogeneity $\left(\tau^{2}=0.344, I^{2}=74 \%\right)$. No study appeared to explain heterogeneity.

Six studies compared a tobacco group (total $n=111$ ) with healthy controls (total $n=100$ ), on a time-based PM task, indicating a negligible-large effect. There was no significant difference between groups with studies that reported contrasting findings. There was high heterogeneity $\left(\tau^{2}=1.46, I^{2}=\right.$ $91 \%$ ). Again, no individual study's removal reduced heterogeneity.

\section{Meta-regression}

Meta-regression analyses revealed an influence of PM task's reliability/validity rating $\left(Q_{\text {model }}(2)=6.86, p=0.032, R^{2}=\right.$ $22 \%)$. Studies using measures with acceptable test-retest reliability and concurrent validity displayed a large effect size
SMD $(k=8)=-0.95395 \%$ CI $(-1.404,-0.502, p<0.001)$. Studies reporting concurrent validity (with objective measures) and questionable or no evidence of test-retest reliability or split-half reliability displayed a larger overall effect size with wider CIs SMD $(k=7)=1.274(0.657$ to 1.890 , $p<0.001)$. While tasks with no evidence of psychometric properties (reliability and validity) displayed smaller effect sizes SMD $(k=8)=-0.35795 \%$ CI $(-0.77,-0.043, p=$ $0.08)$. However, this was not observed for the event-based PM $\left(Q_{\text {model }}(2)=1.959, p=0.367, R^{2}=0 \%\right)$. Categorisation of lifetime dosage displayed no explanatory value.

\section{Discussion}

This study used a meta-analytic approach to examine the magnitude of PM impairments across studies of various licit and illicit recreational drugs. Our analyses revealed that regular users of alcohol, cannabis, ecstasy and opiates performed significantly worse than controls on event- and on time-based PM tasks. Regular smokers performed significantly worse than controls on event-based but not time-based PM tasks, although the effect size estimate for the latter was particularly imprecise with the true effect lying between very large (SMD approximately -2 ) and negligible. The effect sizes for impairments on event-based PM tasks were moderate-large in smokers and heroin users (the latter based on a single study), small-large for alcohol, ecstasy and methamphetamine use, and negligible-large for cannabis. Effect sizes for time-based PM tasks were moderate-large for methamphetamine and opiate use, moderate for cannabis, small-large for ecstasy and negligible-large for tobacco and alcohol. Heterogeneity influenced a number of effect size estimates. As an illustration of the effects of individual studies in determining heterogeneity (as well as overall effect size), exclusion of the study by Platt et al. (2016), resulted in a marked reduction in the heterogeneity of effect sizes in time-based PM performance amongst studies of heavy drinkers, as well as nearly halving the overall effect size.

Despite reflecting the effects of chronic/sub-acute substance use, rather than acute intoxication, the effects summarised here are broadly in line with laboratory studies of acute effects of alcohol on PM (Leitz et al. 2009; Montgomery et al. 2011; Paraskevaides et al. 2010). However, it is important to note that effects of acute alcohol have to date only been investigated in light/social drinkers. The acute-on-chronic effects of alcohol in heavy drinkers have yet to be investigated. In addition, effects reported here on ecstasy (unverified MDMA content) are similar to those found following acute MDMA administration in laboratory settings (Kuypers et al. 2013; Ramaekers et al. 2009; van Wel et al. 
2011). In contrast to the effects of smoked tobacco/nicotine reported here, laboratory-based studies on the acute effects of nicotine have found nicotine to improve PM performance of smokers (Dawkins et al. 2013; Jansari et al. 2013; Rusted et al. 2005; Rusted and Trawley 2006) and 'non-smokers' (Rusted and Trawley 2006), with the exception of one study showing no effect of nicotine on PM in never-smokers (Jansari et al. 2013).

A number of methodological issues were identified within the reviewed studies. For example, there was a high level of polydrug use across studies, particularly in the ecstasy studies. This highlights the difficulty of distinguishing discrete drug effects in studies of non-acutely intoxicated users. Specifically, it is unclear to what extent the observed impairments were due to the primary drug of interest versus other regularly used drugs, or indeed the combination of drugs. In studies of smokers for instance, participants had high levels of alcohol use, some reaching levels as high as those reported in the studies of heavy drinkers. The lack of comprehensive reporting on general drug use in many studies makes it difficult to ascertain the true effect of polydrug use on the effects reported here. In addition, since assessment of bias relating to drug use in the previous $24 \mathrm{~h}$ was 'unclear' in most studies, the role of abstention (or withdrawal) or acute drug effects in the impairments reported here also remains unclear. Related confounds also complicate interpretation. For example, Ludicello et al. (2011) reported high prevalence of AIDS in their sample of methamphetamine users $(60 \%)$ introducing two potential confounds; the cognitive impairment of HIV/AIDS (Watkins and Treisman 2015) and the possible effects of antiretroviral therapy on cognitive performance (Liner et al. 2008).

Many studies had recruited participants from student populations. Higher levels of education and/or cognitive ability (intelligence) in the drug-using groups may have protected against the cognitive impairing effects of drug use (in line with a cognitive reserve hypothesis) and contribute to some of the smaller effect sizes found in the meta-analyses. Other studies recruited their drug-using groups from outside student subject pools and in clinical settings or detox treatment (e.g. Bedi and Redman 2008b; Griffiths et al. 2012; Terrett et al. 2014; Weinborn et al. 2011). For example, Griffiths and colleagues recruited their experimental group from a residential substance misuse service for those with alcohol dependence, and their control group from a university subject pool consisting of students and members of the public. These studies might have greater clinical relevance but they also have a potential for greater bias, associated with for example, the presence of comorbid psychiatric disorders (Hasin et al. 2007) and lower socioeconomic status (Hackman et al. 2010) in more severely affected drug users found in clinical settings. For example, schizophrenia is associated with greater PM impairments than affective disorders (Burton et al. 2018). By recruiting comparison groups from the same or similar populations, matching groups on relevant demographics (e.g. age, educational achievement, premorbid IQ) and using conservative inclusion criteria, future research should aim to increase the internal and external validity of studies.

Surprisingly, lifetime drug dose did not appear to moderate the size of PM impairments. This may have been a result of the relatively crude categorical rating scheme used here, as lifetime dose is a continuous variable. However, this was chosen given the variance in reporting methods on quantifiable drug use. An alternative categorical rating scheme might have been more informative, examining the moderating influence of regularity of drug use (e.g. daily versus less regular use). Moderation analyses within each drug group might have been more informative in determining the moderating role of lifetime drug dose, since cumulative neurotoxicity may be more severe for some drugs (e.g. alcohol and methamphetamine) than others (e.g. smoked tobacco). However, given the small number of studies per drug grouping, such an analysis would have been underpowered.

In most studies, participants were allocated to groups with un-validated measures of drug use. The exception was Weinborn et al. (2011) and Platt et al. (2016). In these studies, a cut-off score on a validated measure of alcohol use was used for group allocation. However, no further verification of drug/ alcohol use was used and as such, healthy controls may have under-reported the quantity and frequency of drug/alcohol use (e.g. see Townshend and Duka 2002). Such under-reporting might have reduced the differences in mean PM performance between control and drug-using groups.

There are a number of limitations inherent in the present review. First, as already noted, the number of studies per drug class was relatively small, which may have adversely affected the precision of effect size estimates. Second, different measures of PM were used across the different studies, with some measures having limited evidence of adequate psychometric properties. Thirdly and relatedly, the effect sizes were characterised by moderate to high levels of heterogeneity, limiting the strength of conclusions about true effect sizes. Fourthly, we limited the inclusion of studies to those covering relatively common drugs associated with problematic use. Other major drug classes, including various novel psychoactive substances that are known to have cognitive impairing effects, were not examined.

\section{Summary}

In studies of non-acutely intoxicated recreational drug users, PM impairments were found in all drug-using groups (heavy drinkers, smokers, and cannabis, ecstasy, methamphetamine or opiate users). However, there were no prospective studies on drug use and PM deficits with a parallel group design, and as such it remains unclear whether PM deficits are a risk factor 
for or consequence of recreational drug use. A number of methodological limitations/sources of bias were identified in most studies. Furthermore, there were high levels of methodological and effect size heterogeneity across studies which limit the strength of conclusions that can be drawn about the true effect size of PM impairments for different drugs. Future studies should seek to address the identified methodological issues and also investigate the effects of different patterns of recreational drug use on event and time PM tasks of differing demand levels.

\section{Compliance with ethical standards}

Conflict of interest The authors declare that they have no conflict of interest.

Open Access This article is distributed under the terms of the Creative Commons Attribution 4.0 International License (http:// creativecommons.org/licenses/by/4.0/), which permits unrestricted use, distribution, and reproduction in any medium, provided you give appropriate credit to the original author(s) and the source, provide a link to the Creative Commons license, and indicate if changes were made.

\section{References}

Bartholomew J, Holroyd S, Heffernan TM (2010) Does cannabis use affect prospective memory in young adults? J Psychopharmacol 24:241-246

Bedi G, Redman J (2008a) Metamemory in recreational ecstasy polydrug users: what do self-reports of memory failures mean? J Psychopharmacol 22(8):872-881

Bedi G, Redman J (2008b) Ecstasy use and higher-level cognitive functions: weak effects of ecstasy after control for potential confounds. Psychol Med 38(9):1319-1330

Behrendt S, Kliegel M, Kraplin A, Buhringer G (2015) Performance of smokers with DSM-5 tobacco use disorder in time-based complex prospective memory. J Psychoactive Drugs 47(3):203-212

Brandimonte M, Einstein GO, McDaniel MA (eds) (1996) Prospective memory; theory and applications. Erlbaum, Hillsdale

Brown SC, Craik FIM (2000) Encoding and retrieval of information. In: Tulving E, Craik FIM (eds) The Oxford handbook of memory. Oxford University Press, New York

Burton CZ, Vella L, Twamley EW (2018) Prospective memory, level of disability and return to work in severe mental illness. Clin Neuropsychol 25:1-12

Cherry K, LeCompte D (1999) Age and individual differences influence prospective memory. Psychol Aging 14:60-76

Cohen J (1988) Statistical power analysis for the behavioral sciences, 2nd edn. Lawrence Erlbaum, Hillsdale

Cuttler C, McLaughlin RJ, Graf P (2012) Mechanisms underlying the link between cannabis use and prospective memory. PLoS One 7(5): 36820

Dawkins L, Turner J, Crowe E (2013) Nicotine derived from the electronic cigarette improves time-based prospective memory in abstinent smokers. Psychopharmacology 227:377-384

Downs SH, Black N (1998) The feasibility of creating a checklist for the assessment of the methodological quality both of randomised and non-randomised studies of health care interventions. J Epidemiol Community Health 52:377-384

Einstein GO, McDaniel MA, Richardson SL, Guynn MJ, Cunfer AR (1995) Aging and prospective memory: examining the influences of self-initiated retrieval processes. J Exp Psychol Learn Mem Cogn 21:996-1007

Fernández-Serrano MJ, Perez-Garcia M, Verdejo-Garcia A (2011) What are the specific vs. generalized effects of drugs of abuse on neuropsychological performance? Neurosci Biobehav Rev 35:377-406

Fisk JE, Montgomery C (2008) Real-world memory and executive processes in cannabis users and non-users. J Psychopharmacol 22(7): 727-736

Gallagher DT, Hadjiefthyvoulou F, Fisk JE, Montgomery C (2014) Prospective memory deficits in illicit polydrug users are associated with the average long-term typical dose of ecstasy typically consumed in a single session. Neuropsychology 28(1):43-54

Grafman J, Litvan I (1999) Importance of deficits in executive functions. Lancet 354(9194):1921-1923

Griffiths A, Morgan HR, Rendell PG, Karimi K, Wanagaratne S, Curran HV (2012) Prospective memory and future event simulation in individuals with alcohol dependence. Addition 107(10):1809-1816

Hackman DA, Farah MJ, Meaney MJ (2010) Socioeconomic status and the brain: mechanistic insights from human and animal research. Nat Rev Neurosci 11:651-659

Hadjiefthyvoulou F, Fisk JE, Montgomery C, Bridges N (2010) Everyday and prospective memory deficits in ecstasy/polydrug users. J Psychopharmacol 25:453-464

Hadjiefthyvoulou F, Fisk JE, Montgomery C, Bridges N (2011a) Prospective memory functioning among ecstasy/polydrug users: evidence from the Cambridge Prospective Memory Test (CAMPROMT). Psychopharmacology 215(4):761-774

Hadjiefthyvoulou F, Fisk JE, Montgomery C, Bridges NJ (2011b) Everyday and prospective memory deficits in ecstasy/polydrug users. J Psychopharmacol 25(4):453-464

Hasin DS, Stinson FSS, Ogburn E, Grant BF (2007) Prevalence, correlates, disability, and comorbidity of DSM-IV alcohol abuse and dependence in the United States. Arch Gen Psychiatry 64:830-842

Heffernan TM, O’Neill TS (2012) Time based prospective memory deficits associatd with binge drinking: evidence from the Cambridge Prospective Memory Test (CAMPROMPT). Drug Alcohol Depend 123:207-212

Heffernan TM, Jarvis H, Rodgers J, Scholey AB, Ling J (2001a) Prospective memory, everyday cognitive failure and central executive function in recreational users of ecstasy. Hum Psychopharmacol 16(8):607-612

Heffernan TM, Ling J, Scholey AB (2001b) Subjective ratings of prospective memory deficits in MDMA ('ecstasy') users. Hum Psychopharmacol 16(4):339-344

Heffernan TM, Moss M, Ling J (2002) Subjective ratings of prospective memory in chronic heavy alcohol users. Alcohol Alcohol 37:269271

Heffernan T, Clark R, Bartholomew J, Ling J, Stephens S (2010a) Does binge drinking in teenagers affect their everyday prospective memory? Drug Alcohol Depend 109:73-78

Heffernan TM, O'Neill TS, Moss M (2010b) Smoking and everyday prospective memory: a comparison of self-report and objective methodologies. Drug Alcohol Depend 122(3):234-238

Heffernan TM, O’Neill TS, Moss M (2012) Smoking-related prospective memory deficits in a real-world task. Drug Alcohol Depend 120:1-6

Heffernan TM, O’Neill TS, Moss M (2013) Smoking-related prospective memory deficits observed on naturalistic everyday memory task. Ir J Psychol Med 30:21-27

Heffernan TM, Carling A, O'Neill TS, Hamilton C (2014a) Smoking impedes executive function and related prospective memory. Ir J Psychol Med 31:159-165 
Heffernan T, Ling J, Bartholomew J (2014b) Self-rated prospective memory and central executive deficits in excessive alcohol users. Ir J Psychol Med 21(4):122-124

Hertzog C, Park DC, Morrell RW, Martin M (2000) Ask and ye shall receive: behavioural specificity in the accuracy of subjective memory complaints. Appl Cogn Psychol 14:257-275

Higgins JP (2008) Commentary: heterogeneity in meta-analysis should be expected and appropriately quantified. Int J Epidemiol 37(5): $1158-1160$

Higgins JPT, Green S (editors) (2011) Cochrane handbook for systematic reviews of interventions Version 5. 1. 0 [updated March 2011]. The Cochrane Collaboration. Available from www.cochrane-handbook. org

Iudicello JE, Weber E, Grant E, Weinborn M, Woods SP, The HIV Neurobiobehavioral Research Center (HNRC) Group (2011) Misremembering future intentions in methamphetamine dependent individuals. Clin Neuropsychol 25(2):269-86

Jansari A, Robert A, Katarina A, Lesley M (2004) The use of virtual reality to assess and predict real-world executive dysfunction: can VR help for work-placement rehabilitation? Brain Impairment 5:110

Jansari A, Froggart D, Edgington T, Dawkins L (2013) Investigating the impact of nicotine on executive functions using a novel virtual reality assessment. Addiction 108:977-984

Jansari AS, Devlin A, Agnew R, Akesson K (2014) Ecological assessment of executive functions: a new virtual reality paradigm. Brain Impairment 15:71-87

Kliegel M, Martin M, McDaniel MA, Einstein GO, Moor C (2007) Realising complex delayed intentions in young and old adults: the role of planning aids. Mem Cogn 35:1735-1746

Knight RG (1998) Prospective memory in aging and neurodegenerative disease. In: Troster AI (ed) Memory in neurodegenerative disease: biological, cognitive and clinical perspectives. Cambridge University Press, New York, pp 172-183

Kuypers KPC, de la Torre R, Farre M, Pujadas M, Ramaekers JG (2013) Inhibition of MDMA-induced increase in cortisol does not prevent acute impairment of verbal memory. Br J Pharmacol 168:607-617

Laloyaux J, Michel C, Mourad H, Bertrand H, Domken M-A, Van der Linden $\mathrm{M}$ et al (2012) Performance on an everyday life activity in persons diagnosed with alcohol dependency compared to healthy controls: relations between computerized shopping task and cognitive and clinical variables. Alcohol Alcohol 47:240-247

Leitz JR, Morgan CJA, Bisby JA, Rendell PG, Curran HV (2009) Global impairments of prospective memory following acute alcohol. Psychopharmacology 205:379-387

Liner KJ, Hall CD, Robertson KR (2008) Effects of antiretroviral therapy on cognitive impairment. Curr HIV/AIDS Rep 5(2):64-71

Ling J, Heffernan TM, Buchanan T, Rodgers J, Scholey AB, Parrott AC (2003) Effects of alcohol on subjective ratings of prospective and everyday memory deficits. Alcohol Clin Exp Res 27(6):970-974

Ling J, Luczakiewicz K, Heffernan TM, Stephens R (2010) Subjective rating of prospective memory deficits in chronic alcohol users. Psychol Rep 106:905-917

Ludicello JE, Weber E, Grant I, Weinborn M, Woods SP (2011) Misremembering future intentions in methamphetamine-dependent individuals. Clin Neuropsychol 25(2):269-286

Marshall A-M, Herffernan T, Hamilton C (2016) The synergistic impact of excessive alcohol drinking and cigarette smoking upon prospective memory. Frontiers in Psychiatry, 7, 75.

McDaniel MA, Einstein GO (2000) Strategic and automatic processes in prospective memory retrieval: a multiprocess framework. Appl Cogn Psychol 14:S127-S144

McHale S, Hunt N (2008) Executive function deficits in short-term abstinent cannabis users. Hum Psychopharmacol 23(5):409-415

Montgomery C, Fisk JE (2007) Everyday memory deficits in ecstasypolydrug users. J Psychopharmacol 21(7):709-717
Montgomery C, Hatton NP, Fisk JE, Ogden RS, Jansari A (2010) Assessing the functional significance of ecstasy-related memory deficits using a virtual paradigm. Hum Psychopharmacol Clin Exp 25(4):318-325

Montgomery C, Ashmore KV, Jansari A (2011) The effects of a modest dose of alcohol on executive functioning and prospective memory. Hum Psychopharmacol Clin Exp 26(3):208-215

Montgomery C, Seddon AL, Fisk JE, Murphy PN, Jansari A (2012) Cannabis-related deficits in real world memory. Hum Psychopharmacol 27(2):217-225

Paraskevaides T, Morgan CJA, Leitz JR, Bisby JA, Rendell PG, Curran HV (2010) Drinking and future thinking: acute effects of alcohol on prospective memory and future simulation. Psychopharmacology 208:301-308

Platt B, Kamboj SK, Italiano T, Rendell PG, Curran HV (2016) Prospective memory impairments in heavy social drinkers are partially overcome by future event simulation. Psychopharmacology 233(3):499-506

Ramaekers JG, Kuypers KPC, Wingen M, Heinecke A, Formisano E (2009) Involvement of inferior parietal lobules in prospective memory impairment during acute MDMA (ecstasy) intoxication: an event-related fMRI study. Neuropsychopharmacology 34:16411648

Raskin S, Buckheit C, Sherrod C (2010) Memory for intentions test. Psychological Assessment Resources, Inc., Lutz

Rendell P, Craik F (2000) Virtual week and actual week: age-related differences in prospective memory. Appl Cogn Psychol 62:43-62

Rendell PG, Gray TJ, Henry JD, Tolan A (2007) Prospective memory impairment in "ecstasy" (MDMA) users. Psychopharmacology 194(4):497-504

Rendell PG, Mazur M, Henry JD (2009) Prospective memory impairment in former users of methamphetamine. Psychopharmacology 203(3): $609-616$

Rodgers J, Buchanan T, Scholey AB, Heffernan TM, Ling J, Parrott A (2001) Differential effects of ecstasy and cannabis on self-reports of memory ability: a web-based study. Hum Psychopharmacol 16(8): $619-625$

Rodgers J, Buchanan T, Scholey AB, Heffernan TM, Ling J, Parrott AC (2003) Patterns of drug use and the influence of gender on selfreport of memory ability in ecstasy users: a web-based study. J Psychopharmacol 17(4):389-396

Rusted JM, Trawley S (2006) Comparable effects of nicotine in smokers and non-smokers on a prospective memory task. Neuropsychopharmacology 31:1545-1549

Rusted JM, Trawley S, Heath J, Kettle G, Walker H (2005) Nicotine improves memory for delayed intentions. Psychopharmacology 182:355-365

Sanderson S, Tatt ID, Higgins JP (2007) Tools for assessing quality and susceptibility to bias in observational studies in epidemiology: a systematic review and annotated bibliography. Int J Epidemiol 36: 666-676

Seed JA, Dahabra S, Heffernan TM, Robertson B, Foster K, Venn H (2005) Everyday memory and related processes in patients with eating disorders. Clin Eff Nurs 8:176-188

Terrett G, McLennan SN, Henry JD, Biernacki K, Mercuri K, Curran HV, Rendell PG (2014) Prospective memory impairment in long-term opiate users. Psychopharmacology 231:2623-2632

Titov N, Knight RG (2001) A video-based procedure for the assessment of prospective memory. Appl Cogn Psychol 15:61-81

Townshend JM, Duka T (2002) Patterns of alcohol drinking in a population of young social drinkers a comparison of questionnaire and diary measures. Alcohol Alcohol 37:187-192

Uttl B, Kibread M (2011) Self-report measures of prospective memory are reliable but not valid. Can J Exp Psychol 65:57-68

van Wel JHP, Kuypers KPC, Theunissen EL, Bosker WM, Bakker K, Ramaekers JG (2011) Blockade of 5- $\mathrm{HT}_{2}$ receptor selectively 
prevents MDMA-induced verbal memory impairment. Neuropsychopharmacology 36:1932-1939

Viechtbauer W (2010) Conducting meta-analyses in R with the metafor package. J Stat Softw 36(3):1-48

Watkins C, Treisman GJ (2015) Cognitive impairment in patients with AIDS - prevalence and severity. HIV AIDS 7:35-47

Weinborn M, Woods SP, Nulsen C, Park K (2011) Prospective memory deficits in ecstasy users: effects of longer ongoing task delay interval. J Clin Exp Neuropsychol 33(10):1119-1128

Wells GA, Shea B, O'Connell D, Peterson J, Welch V, Losos M et al (2011) The Newcastle-Ottawa scale (NOS) for assessing the quality of nonrandomised studies in meta-analyses. Retrieved from http:// www.ohri.ca/programs/clinical_epidemiology/oxford.asp

Wilson BA, Cockburn J, Baddeley AD (1985) The rivermead behavioural memory test. Thames Valley Test Co., Bury St. Edmunds
Wilson BA, Emslie H, Foley J, Shiel A, Watson P, Hawkins K, Groot Y, Evans J (2005) The Cambridge prospective memory test. HarcourtAssessment, London

World Health Organization (2009) Global health risks: mortality and burden of disease attributable to selected major risks. WHO Press, Geneva

Zakzanis KK, Young DA, Campbell Z (2003) Prospective memory impairment in abstinent MDMA ("ecstasy") users. Cogn Neuropsychiatry 8(2):141-153

Publisher's note Springer Nature remains neutral with regard to jurisdictional claims in published maps and institutional affiliations. 